10,95950
9,195 SANDIA REPORT

\author{
SAND95-8226 • UC-407 \\ Unlimited Release \\ Printed August 1995
}

\title{
Risk-Based Analyses in Support of California Hazardous Site Remediation
}

\author{
J. T. Ringland
}

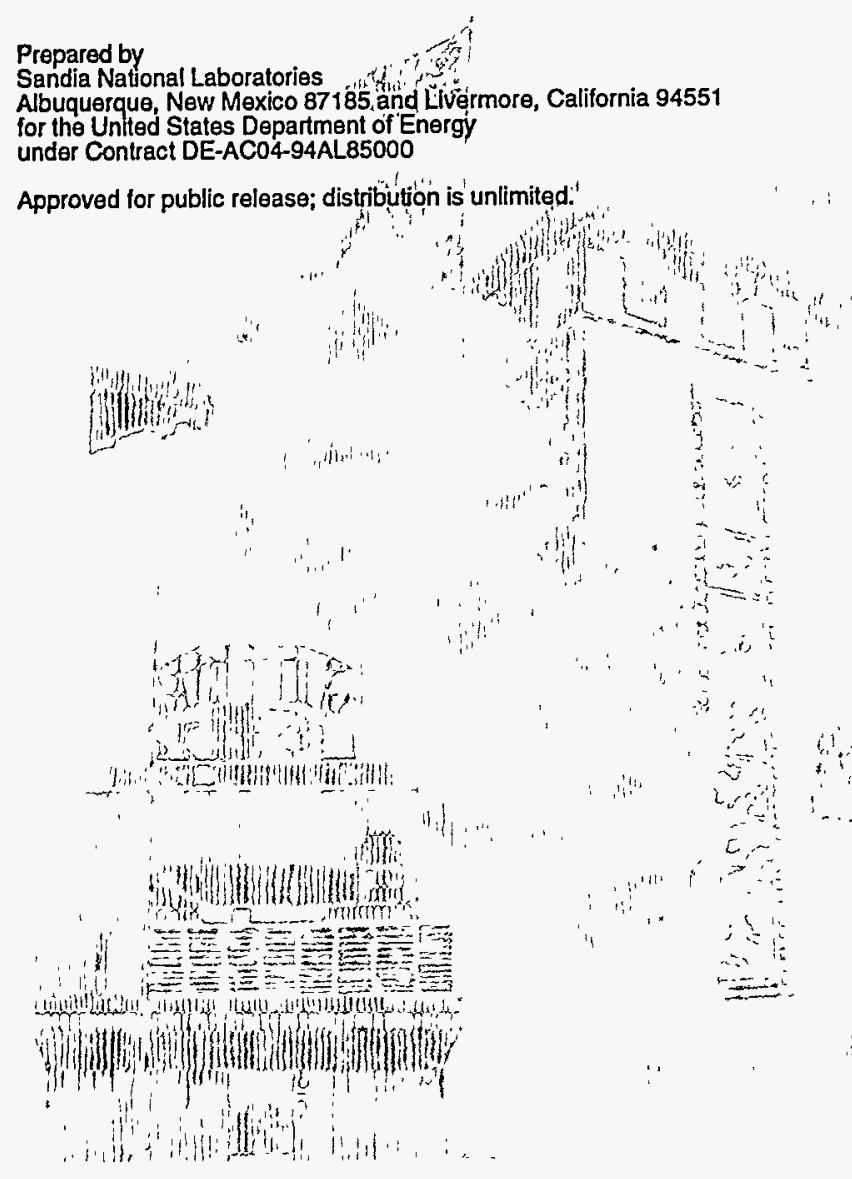




\begin{abstract}
Issued by Sandia National Laboratories, operated for the United States Department of Energy by Sandia Corporation.

NOTICE: This report was prepared as an account of work sponsored by an agency of the United States Government. Neither the United States Government nor any agency thereof, nor any of their employees, nor any of the contractors, subcontractors, or their employees, makes any warranty, express or implied, or assumes any legal liability or responsibility for the accuracy, completeness, or usefulness of any information, apparatus, product, or process disclosed, or represents that its use would not infringe privately owned rights. Reference herein to any specific commercial product, process, or service by trade name, trademark, manufacturer, or otherwise, does not necessarily constitute or imply its endorsement, recommendation, or favoring by the United States Government, any agency thereof or any of their contractors or subconractors. The views and opinions expressed herein do not necessarily state or reflect those of the United States Government, any agency thereof or any of their contractors or subcontractors.
\end{abstract}

This report has been reproduced from the best available copy.

Available to DOE and DOE contractors from:

Office of Scientific and Technical Information

P. O. Box 62

Oak Ridge, TN 37831

Prices available from (615) 576-8401, FTS 626-8401

Available to the public from:

National Technical Information Service

U.S. Department of Commerce

5285 Port Royal Rd.

Springfield, VA 22161 


\section{DISCLAIMER}

Portions of this document may be illegible in electronic image products. Images are produced from the best available original document. 
SAND95-8226

Unlimited Release

Printed August 1995

\title{
RISK-BASED ANALYSES IN SUPPORT OF CALIFORNIA HAZARDOUS SITE REMEDIATION
}

\author{
James T. Ringland \\ Systems Research Department \\ Sandia National Laboratories/California
}

\begin{abstract}
The California Environmental Enterprise (CEE) is a joint program of the Department of Energy (DOE), Lawrence Livermore National Laboratory, Lawrence Berkeley Laboratory, and Sandia National Laboratories. Its goal is to make DOE laboratory expertise accessible to hazardous site cleanups in the state. This support might involve working directly with parties responsible for individual cleanups or it might involve working with the California Environmental Protection Agency to develop tools that would be applicable across a broad range of sites. As part of its initial year's activities, the CEE supported a review to examine where laboratory risk and risk-based systems analysis capabilities might be most effectively applied. To this end, this study draws the following observations. The labs have a clear role in analyses supporting the demonstration and transfer of laboratory characterization or remediation technologies. The labs may have opportunities in developing broadly applicable analysis tools and computer codes for problems such as site characterization or efficient management of resources. Analysis at individual sites, separate from supporting lab technologies or prototyping general tools, may be appropriate only in limited circumstances. In any of these roles, the labs' capabilities extend beyond health risk assessment to the broader areas of risk management and risk-based systems analysis.
\end{abstract}

DISTRIBUTION OF THIS DOCUMENT IS UNLIMITED

$3 / 4$

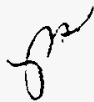




\section{CONTENTS}

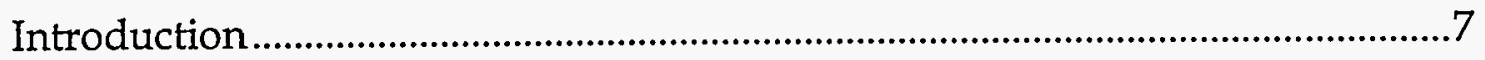

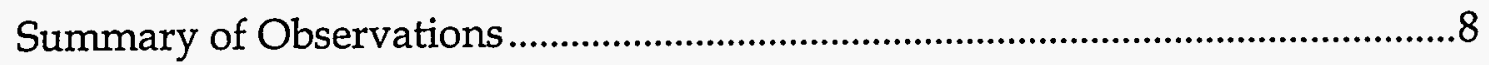

Support for technology development..............................................................

Development of analysis tools and computer codes ..................................

Participation in risk and systems analyses at individual sites ....................10

Overview of the Cleanup Process ..........................................................................11

The DTSC Voluntary Site Cleanup Program ..........................................................12

Representative Cleanups and Associated Issues .................................................13

Fresno ..............................................................................................13

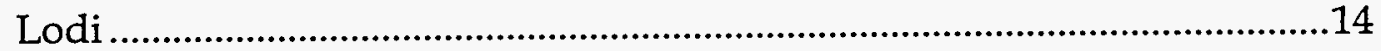

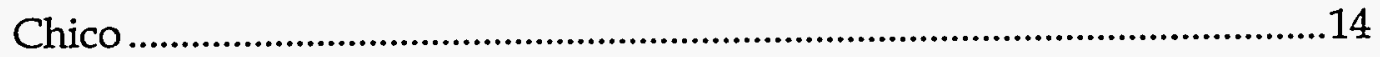

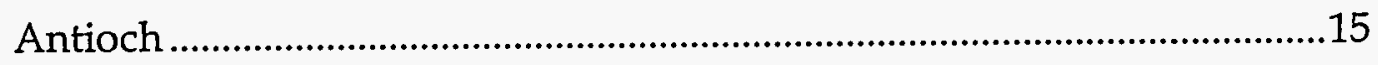

Risk-based Analysis in the Cleanup Study Phase...................................................16

Site characterization ..................................................................................16

Remediation options .............................................................................18

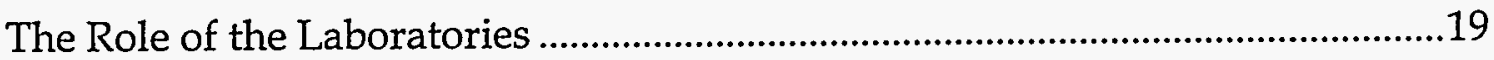

Support for laboratory technologies.............................................................19

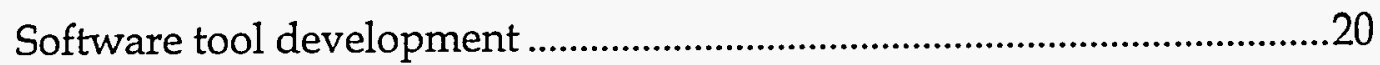

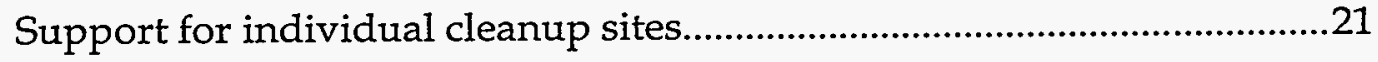

Concluding Comments: Managing The Relationships .........................................22 


\section{ILLUSTRATIONS}

No.

Page

1. The Cleanup Process ...............................................................................................11

2. Risk-Based Analyses in the Study Phase........................................................16 


\section{RISK-BASED ANALYSES IN SUPPORT OF CALIFORNIA HAZARDOUS SITE REMEDIATION}

\section{Introduction}

The Department of Energy and its three laboratories in California, Lawrence Berkeley Laboratory, Lawrence Livermore National Laboratory, and Sandia National Laboratories, established the California Environmental Enterprise (CEE) to provide a vehicle to make laboratory technologies and expertise more accessible for state-level hazardous site cleanups. It was envisioned that this expertise would be of value both to state regulators, primarily the California Environmental Protection Agency's Department of Toxic Substance Control (Cal/EPA DTSC), and to the private sector. Among the latter, participants in DTSC's Voluntary Site Cleanup (Walk-In) Program were seen as a natural group who might seek the laboratories' expertise.

When the technology transfer from the laboratories is thought of in this context, remediation and characterization technologies come to mind first. However, information technologies offer important contributions too. These include databases and computer networks to link groups doing similar work and coordinate complex cleanups, decision support systems to guide site cleanup, and risk analyses. This report discusses technology transfer in the latter information and analysis areas. Other CEE efforts are examining appropriate roles for laboratory remediation and characterization technologies.

In fiscal year 1994, the CEE's first year, Sandia supported two such information technology activities: enhanced development of the EnviroTRADE environmental technology database and risk assessment methodology development. Risk assessment was included because Sandia has some experience in environmental risk analysis, extensive experience in related engineering safety risk analysis, and a well-developed systems analysis capability for guiding technology development and deployment. Both Lawrence Livermore and Lawrence Berkeley also have significant analysis capabilities, but these were not supported by the CEE this year. The CEE hoped to be involved in one or two specific cleanup sites in 1994. The Risk Assessment Methodology Development Task was planned to support the demonstration of laboratory remediation and characterization technologies and to demonstrate how 
laboratory analysis technologies might be utilized at one or more or these specific sites. Because of administrative issues, however, there was involvement at only one site, the Hickmott Cannery in Antioch, California which began very late in fiscal 1994. This interaction has continued in fiscal year 1995.

Because of this, the fiscal year 1994 Risk Assessment Methodology Development Task was redirected from actually applying risk-based analysis at one or two sites to reviewing how laboratory risk and risk-based analyses might be applied to support state-overseen cleanups. The scope of this potential support includes direct participation at individual sites, which would be funded at least in part by the responsible party. It also includes more indirect tool development and technology support activities, which would require government funding. The primary objective of this report is to provide guidance to laboratory management, the $\mathrm{CEE}$, and $\mathrm{DOE}$ on where appropriate opportunities for utilizing laboratory risk-based analysis capabilities may and may not lie. In this context, an "appropriate opportunity" is one in which where laboratory technical capabilities match technical needs and where the laboratories offer a capability not available in and complementary to the private environmental consulting community. The discussion here is especially relevant to those in the laboratories with experience in risk and systems analysis, but with limited experience in site remediation.

To this end, in the late spring and summer of 1994, there were discussions at DTSC with Allen Wolfenden, who is in charge of the Voluntary Site Clean-up (Walk-In) Program, Gene Riddle, a project manager overseeing several individual cleanups, and Jerry Marcott, his supervisor, who has a broad perspective of the sites actually being cleaned up. There were also a variety of discussions among groups within the laboratories. Some observations from the first interactions at Antioch are also included here.

\section{Summary of Observations}

The roles for the risk and systems analysis in hazardous site cleanups can be divided into three broad categories:

- Support for characterization and remediation technology development

- Development of broadly applicable analysis tools and computer codes

- Participation in risk and systems analyses at individual sites

The following paragraphs discuss each of these. The opportunities for technology transfer of laboratory analysis capabilities appear strongest in the first two categories; the latter is an appropriate role for the laboratories only under limited circumstances. 
To each, the labs can bring a variety of risk management and systems analysis capabilities. In the context of site remediation, the words risk assessment are generally applied, narrowly, to the determination of the cleanup levels at which the chances of residual hazards to human health and the environment are below some mandated threshold. At many smaller sites this is not a large task. Once a site is characterized, many standard assumptions can often be reasonably applied. However, risks of many other sorts - technical risks associated with new technologies and site characterization uncertainties, to give two examples need to be considered in conjunction with health risk in the choice of remediation approach. The tools of systems and decision analysis, with which the labs have considerable experience and which underlie risk assessment, deal with these broader risks and uncertainties.

\section{Support for technology development}

Transfer of laboratory-developed characterization or remediation technology requires an understanding of costs, benefits, and technical risks both by the technologist and the potential user. The laboratory analysis community is in a natural position to help develop this information.

This support could take the form of internally supported analyses and reviews of specific lab technologies that identify where a technology might be best applied and where additional development might prove advantageous. The customer of the analysis would be the developers of the technology themselves.

This support could also take the form of partnerships with private contractors working on a site to understand the costs, benefits, and risks associated with a laboratory technology. In this role, laboratory risk management support is part of the package with laboratory characterization or remediation technology. However, since information developed at one site for a particular technology should carry over to other sites, even in the role, the ultimate beneficiary of the analysis may be the developers of the remediation or characterization technology.

\section{Development of analysis tools and computer codes}

Tool building is a familiar way of transferring analysis technologies. Substantial work has already been done in the laboratories on risk assessment tools that help determine appropriate cleanup levels. Opportunities exist for tools that guide site characterization. Opportunities also exist for tools that integrate information, uncertainty, and risk to manage resources efficiently and structure remediation decisions. In this role, the primary customer for analysis product is not the party responsible for an individual remediation site, although he or she 
may benefit. The primary customers are the sponsors and users of the analysis tool. This may be the collection private parties who will use the tools once built. This may also be another government body directly involved in site remediation such as Cal/EPA. The results of the work should be directly applicable to a broader range of sites than any individual demonstration site.

\section{Participation in risk and systems analyses at individual sites}

Laboratory risk-management activities at individual remediation projects separate from the roles above - will be appropriate only in specialized circumstances. There are two critical issues. First, the labs must be careful not to do work that an environmental contractor could do, even if they can leverage DOE funding that would otherwise be unavailable to the responsible party. Participation at an individual site, in partnership with the contractor community, is appropriate only if the issues are sufficiently out of the ordinary that the laboratories can develop innovative risk, systems or decision analysis approaches beyond those that are available privately. This raises the second critical issue. Many individual sites present time or resource limitations that constrain this. These opportunities may be present only in the largest of the private cleanups, and, with some external funding, with municipal, military, or other government cleanups. There may also be circumstances where the labs can provide either special expertise or an independent viewpoint not available in the private community.

These two concerns are at least partially eased if the work at a particular site if done is in the context of guiding a laboratory remediation technology demonstration or prototyping broadly applicable analysis tools. Regarding the first issue, in neither of these contexts would the laboratory risk management community be taking on work that a contractor would naturally do. The laboratory analysis community has a natural role in working through unique risk and analysis questions raised in applying a new laboratory technology. Private contractors may, of course, also have a significant role at such a demonstration site in analysis questions that are not unique to the new technology. In the case of software prototyping, while there is commercial risk and decision analysis software development, there are many areas for cooperative work. Regarding the second issue, by linking an analysis project to something larger than a single remediation site, time or resource limitations are eased.

The following sections develop the background for these observations. To provide background, the next sections summarize the cleanup process, introduce the DTSC Voluntary Cleanup program, and illustrate some the issues via a discussion of four representative sites. Following that is a discussion of the application of risk-based analyses in the process of developing a Remedial 
Action Plan for a site. The final section returns to the issues that define appropriate laboratory roles.

\section{Overview of the Cleanup Process}

Whether a site cleanup is voluntary or mandated by the state, the basic procedure follows that in the National Contingency Plan for Superfund sites. Figures 1 illustrates the overall process. The process begins with a Preliminary Endangerment Assessment which scopes the situation, makes a preliminary identification of responsible parties, and which, if necessary, leads to removal actions to eliminate any immediate danger. Following that is a fairly formal study phase. This involves an investigation of sources and spread of contamination (the Remedial Investigation or RI) and a formal review of cleanup alternatives (the Feasibility Study or FS). These are presented in a Remedial Action Plan (RAP), together with the site owner's preferred course of action. This may be acceptable to DTSC or there may be further negotiations. For

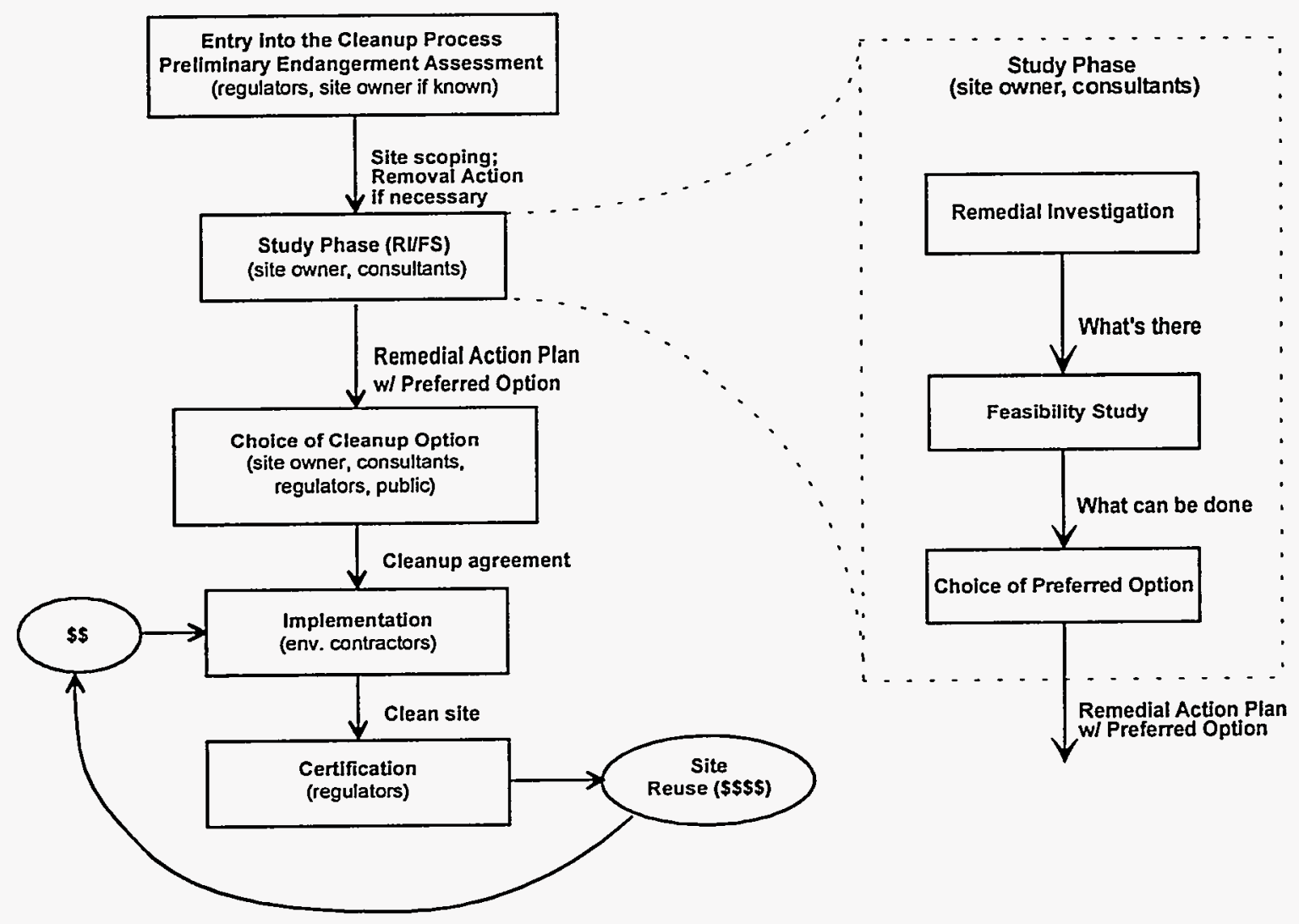

Figure 1. The Cleanup Process 
voluntary cleanups, the owner is responsible for the actual remediation work with DTSC oversight. DTSC certification that the site is clean then allows redevelopment to proceed. In redevelopment cleanups, it is clearly the intent of the developer that revenue from returning the site to productive use will more than offset the cost of this remediation. Indeed, sale or redevelopment may be the only practical way to fund a cleanup.

There are a number of reasons why an owner might voluntarily clean up a site. State law requires that any owner of non-residential property who has reason to believe there has been a hazardous release on a site must notify potential buyers or renters. Financing on a purchase or lease usually is not available until a lender is assured the site is clean. If residential development (housing, schools, day care centers, hospitals) is planned within 2000 feet of a property where there is reason to expect contamination, the owner of the development must request DTSC review of the potentially contaminated site. Such a DTSC review may also be requested by the owner of the potentially contaminated property or the local city or county having jurisdiction. On contaminated properties there be can no new use except modification or expansion of an industrial or manufacturing facility without variance from the DTSC. The latter depends on the projected use of the site. Such a hazardous waste property can only be subdivided for the purpose of separating non-hazardous from hazardous portions. On sites bordering such properties (within 2000 feet), residential development is prohibited. Site remediation would be needed to remove these restrictions.

Many enforcement actions and some voluntary cleanups entered the process when contamination in municipal drinking water wells was traced back to individual properties. In California, many municipal wells were tested for the first time in the early 80's. Many hazardous releases, some quite old, were found in this way. Now that all public wells have been tested, new contamination often means a new source.

\section{The DTSC Voluntary Site Cleanup Program}

The Voluntary Site Cleanup (Walk-In) Program provides a means for site owners or other responsible parties to get regulatory review services in voluntary cleanups. This assistance is paid for by the responsible party.

DTSC accepts sites into the Voluntary Site Cleanup Program based on the match of site complexity to the responsible party's resources and experience. The general concept is that the program will deal with relatively simple, low risk sites. However, complex sites held by experienced firms may be in the program. For example, the big California utility companies - Southern California Gas, Southern California Edison, and Pacific Gas and Electric - have sites in the 
program. Some large corporate landowners, while very cooperative, prefer for legal reasons to operate under legal mandate than through the Voluntary Site Cleanup Program. This gives them additional legal tools to deal with tenants who have created contamination problems.

The Voluntary Site Cleanup Program has widely advertised its services since late 1993. In June 1994, Cal/EPA's Region 1, which includes all of Northern California except the coastal and Bay Area counties, has about 10 sites in the Voluntary Site Cleanup Program. The other regions added 10 to 20 more at that time. At that time, one cleanup had already been completed: a simple removal of lead in a schoolyard.

Many cleanups in the state are not managed through DTSC. The Water Boards handle some, including underground tank cleanups. In some cases the counties take the lead in certifying that a cleanup is completed and a site is ready for reuse. Orange County, for example, is very active in this area. It should also be noted that lenders and financiers are important de facto regulators since they do not want to foreclose on contaminated property.

\section{Representative Cleanups and Associated Issues}

To get a better sense of what is involved, it is worthwhile to look at a few sites in more detail. The following four situations illustrate where the issues do and do not lie in smaller remediation situations. Except for the fourth example, the Hickmott Cannery in Antioch, these are not Voluntary Site Cleanup Program sites. All, however, illustrate issues that might be present in cleanups of that scale. These are presented as case histories. The following sections will draw some general themes from these.

\section{Fresno}

In Fresno, a manufacturer had been dumping solvents "out by the railroad tracks" for several decades. Traces of solvent have appeared in water from several of Fresno's municipal wells, so the city has been carbon treating its well water. Characterizing the actual location of the solvent plume has been a problem both because of the complexity of the geology and because of the limited resources available. The site is just south of the San Joaquin river and there are a variety of ancient buried gravel stream beds that the solvent preferentially follows. Municipal wells have been one source of location data and a limited number of wells and bore holes have been dug to further localize the plume. The responsible company, while very cooperative, only has the ability to contribute about $\$ 750,000$ a year to all remediation operations, which 
include, but are not limited to, site characterization. It is not feasible to drill scores of exploratory wells. Remediation will be carried out over a twenty year period or so by pumping and treating contaminated water. Because of the uncertainties in where the underground contamination lies, however, this pumpand-treatment operation may have to be adjusted as its effectiveness is tracked. DTSC would welcome anything that would help them make better use of the data they have, or that would identify particularly useful information that would be worth collecting given the limited resources available.

\section{Lodi}

In Lodi, as in Fresno, contaminated drinking water wells led to a search for a source of both dry cleaning fluids and trichlorethane (TCE). DTSC traced one TCE plume to a manufacturer who dumped solvents. However, they were not able to trace all of the contamination back to individual sources. It appears some contaminants were dumped into the city sewers from which they leaked into the ground though cracks in pipes and joints. (DTSC uses small video cameras to inspect sewers from the inside. Cracks and bad joints are fairly easy to spot.) Some soil vapor extraction is being used to remove contaminants from the vadose zone. The city's municipal wells have been closed because of this contamination, but the city is considering reopening them and treating the pumped water. The usual approach, removing the organics by running them through activated carbon, is expensive: once the carbon absorbs the hazardous materials, it is itself a hazardous waste that must be handled carefully. The city is reviewing the use of ultraviolet light to destroy the organics.

\section{Chico}

Yet a third variation on groundwater contamination comes from Chico. This is an enforcement action, not a voluntary cleanup, but this site illustrates some other remediation issues. There are five separate solvent plumes. The geology is much like that in Fresno with buried gravels. However, unlike Fresno, significant resources have been applied to site characterization. A relatively complex hydro-geological model of the area has been constructed. Twenty boreholes were dug to map out one plume a mile long and a few hundred feet wide. Soil vapor extraction, pump-and-treat, and air-sparging techniques are all being used with carbon filtering to remove contaminants. The responsible party for a TCE plume has proposed in situ bio-remediation. Bacteria would be introduced into the solvent-bearing groundwater to break the contaminants down into simpler and presumably harmless compounds. The state has limited experience with this technology and has been actively reviewing the literature to understand the strengths and risks. It appears that unless the strategy for a new biotechnology approach is quite compelling, it will initially be accepted only 
where the risks to public health are not large. Where drinking water is directly involved, more proven approaches will be preferred. Part of this is health related, but part is related to community reluctance of having bacteria (of any sort) introduced into the water supply.

\section{Antioch}

The primary problem at the Hickmott Cannery in Antioch is soil gasses hydrogen cyanide, hydrogen sulfide, and some methane - from buried vegetable and fruit debris decaying in the absence of oxygen. The sulfur in the hydrogen sulfide appears to be coming from gypsum wallboard that had been dumped at the site for fill. There are also some hydrocarbons in the soil and some localized heavy metal contamination. The developer wishes to build condominiums adjacent to, but not directly on, these contaminated areas. No construction would begin, of course, until these remediation goals for the site had been met.

The responsible party and environmental consultants are still working on cleanup strategies. They invited DOE representatives from the three California labs and from Savannah River, which has some experience in remediating a site of this type, to comment. It is worth noting that the site developer was initially quite wary of this interaction, perhaps fearing delay or excessive cost in a cleanup approach he might, by circumstances, be forced to use.

Very little of the initial discussion with the labs involved the mechanics of a formal health risk analysis. (The discussion indicated this work was being carried out by one of the environmental contractors. Health risk is, of course, the central issue and there have been extensive discussions of the issue.) Other types of risks, however, were central to that discussion. Technical risk is a major issue for innovative approaches. The Savannah River team proposed a bioremediation approach to hasten the decay of the vegetable matter. It was clear that that would probably only be acceptable if there was a monitoring scheme to clearly demonstrate it its progress. Financial risk is, of course, a big issue for the developer. The delay that would occur if the bio-remediation approach was not meeting its goals would have financial consequences. There was also considerable discussion concerning the public perception of risk. Future condominium purchasers might reasonably want a very, very high degree of assurance that the hydrogen cyanide and hydrogen sulfide in the soil beneath their homes was gone and could not be regenerated. A remediation option, for example, that allowed trace amounts of soil gasses to be regenerated after the site is developed could be quite safe if there was mechanism in place to continuously remove them. Such an approach, however, might or might not be seen as acceptable by someone purchasing a home. 


\section{Risk-based Analysis in the Cleanup Study Phase}

Figure 2 illustrates the steps leading to the development of a Remedial Action Plan and the ways risk-based analyses can enter into the planning process. These will be discussed below.

\section{Site characterization}

The first steps are the Preliminary Endangerment Assessment and Remedial Investigation to locate the nature, sources, and spread of contamination. In the preliminary assessment, DTSC identifies whether a site poses an immediate threat to health and the environment and makes a preliminary identification of responsible parties. The remedial investigation is a more detailed examination of the type and extent of contamination.

With metal cleanups these steps are often relatively straightforward. The material does not move from where it was placed, and it may not be all that
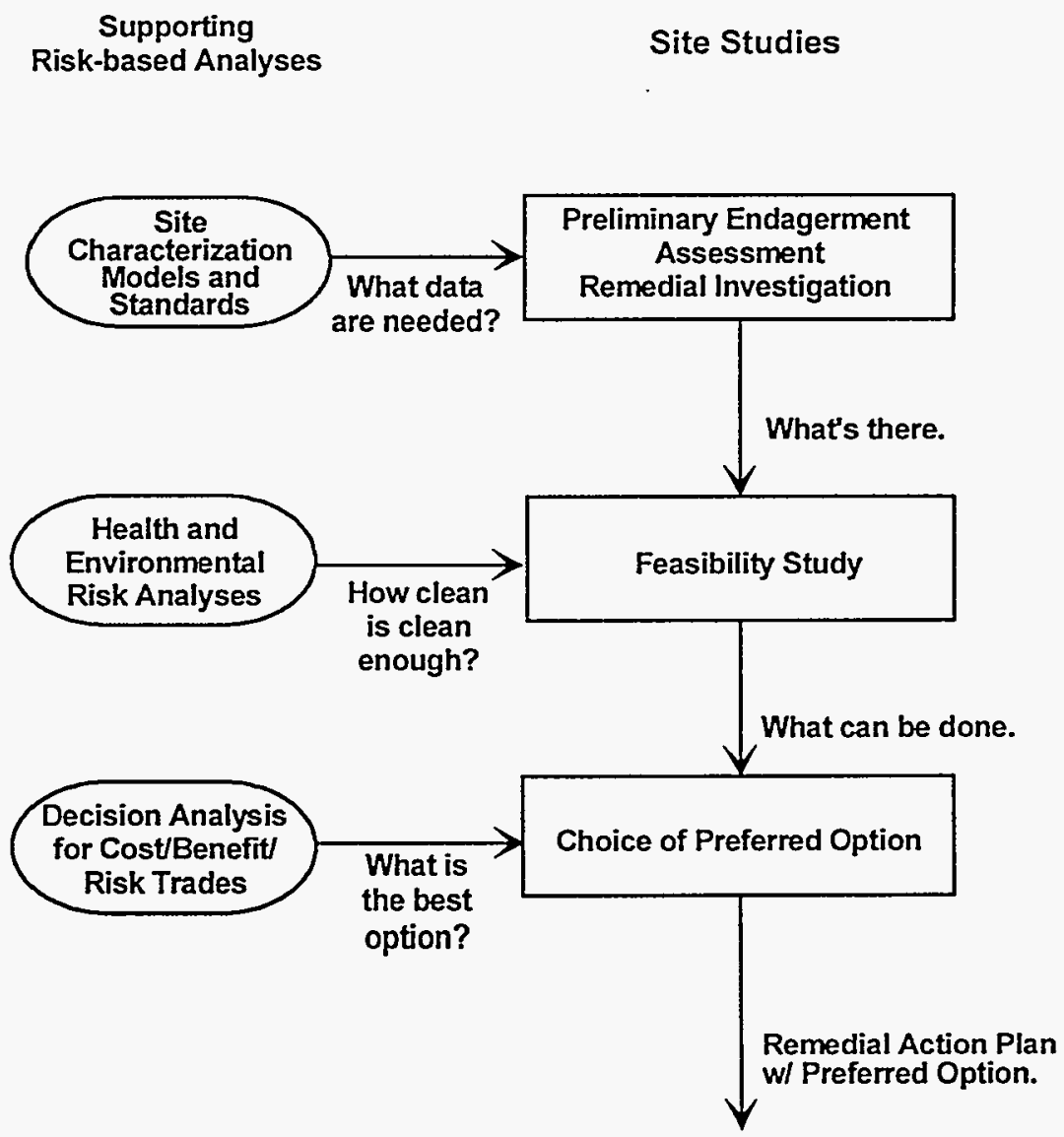

Figure 2. Risk-Based Analyses in the Study Phase 
difficult to map out the edges of contamination. Complex industrial sites, of course, can provide exceptions. Sampling and lab analysis are familiar techniques, but on-site $X$-ray fluorescence has been used successfully in at least one case.

Deeper soil and groundwater contamination sites present more complexity. If contamination is first detected in a drinking water well, considerable site-specific detective work may be needed during the preliminary assessment to locate the source. A common approach is to drill three monitoring wells around the contaminated one; two up gradient and one down to identify the direction from which the contaminant appears to be coming. If subsequent sampling wells identify higher and higher concentrations, then a point source can usually be located. If not, then the source is more diffuse, like a dry well or a sewer, as was the case in Lodi. Reviewing past and present uses of the land above the contamination may provide valuable information in the search. Once sources are found, they can be stopped and, if necessary, immediate removal action initiated.

Once the source is located, the investigation moves on to map out the pathways by which the contaminants can affect human health or the environment. This involves both mapping contamination in individual strata and identifying points of entry from one stratum to another. Examples of the latter might be wells that penetrate what would otherwise be an impermeable layer. The goal is to locate all contaminated zones. There have been draft standards for how to carry out this characterization in circulation at DTSC for over two years. However, it has proven hard to produce general standards given the considerable variations from site to site. Note that the characterization efforts in Fresno, Lodi, and Chico discussed in the previous section vary considerably because of the geology, the nature of the sources, and the resources available.

There are several statistical and risk-based systems modeling issues in site characterization. Especially at the more complex sites, organizing and effectively disseminating characterization data may not be trivial. Ideally, data should lead to the development of a site model, and the needs of that modeling effort should help determine what data to collect. It may also be possible to locate investigation wells so that they are good candidates for remediation pumping or monitoring. This requires that the locations of the investigation wells be wisely chosen with incomplete information, but there is some hope at Fresno, for example, of being able to do this. All this leads to a complex decision analysis question: how much data collection, and associated expense, is sufficient to define reasonable cleanup options?

In voluntary cleanups, these tasks are carried out by environmental or engineering consultants hired by the owner of the contaminating source. In mandated cleanups, private consultants hired by the responsible party may be 
involved with active DTSC oversight, or the state may contract the work directly. These efforts may be considerable, as at the Chico site. And, as noted in the discussion about the Fresno site, DTSC would welcome means to make better use of data or to better guide data collection.

\section{Remediation options}

The next step is to identify potential ways to remediate the site. This involves identifying levels to which contaminants must be reduced, identifying remediation approaches, and evaluating each. This leads to a remedial action plan (RAP) which lays out these alternatives and the responsible party's preferred course of action. This plan provides a basis for negotiation and agreement between $\mathrm{Cal} / \mathrm{EPA}$ and the responsible party on remediation methods.

While cleanup levels are based on the risk to health and safety, these often do not come from complex site-specific risk assessments. If drinking water is contaminated, the Federal Safe Drinking Water Act Maximum Concentration Levels (MCLs) or equivalent and sometimes stronger state action levels apply. For many situations, such as surface heavy metal contamination, there are some fairly straightforward federal EPA conventions. A major determinant then becomes one of identifying the potential future land use. This defines which exposure mechanisms will be active. Exposure mechanisms include such things as inhalation (dust, escaped soil gasses), dermal contact, soil ingestion (for example, from produce grown in a residential garden), and so forth. Some sites require more complex site-specific risk analyses. The generation rates and consequences of the soil gasses at the Hickmott cannery in Antioch present an example of this. These issues may depend on the specific details of the remediation option as well as the details of the subsequent site development.

As illustrated in the case studies, technology review and selection presents riskbased trade-offs involving several factors: cost, timing, effectiveness and technical risk, and risk perception. Familiar approaches tend to be expensive: hauling large quantities of soil, many years of pumping and treating, etc. (Even the latter is sometimes more of a containment strategy rather than complete removal strategy.) New technologies can, hopefully, reduce costs, but the technical risks are higher, and time can be a major issue if new technologies delay cleanup and hence redevelopment of a property. Antioch provides an illustration of this. The suggestion made in the DOE meeting was to begin with bio-remediation approaches and be prepared to fall back to more traditional ones if the former were not meeting a set of well-defined goals regarding the reduction in overall carbon content in site sediments. Cost and time are reduced if everything works; they are increased if not. Finally, note that the risks perceived by the public and their confidence that they are being fully addressed may be more important to a project than the risks assessed by scientists and 
engineers. The very different concerns about bio-remediation of drinking water in Chico and the need for a clear demonstration of cyanide removal at Antioch both illustrate situations where public acceptance and confidence are critical risk issues.

\section{The Role of the Laboratories}

The previous sections amply demonstrate that risk-based analyses - of which risk assessment per se is only one - occur throughout the cleanup process. The laboratories have skills in these areas. However, many of the tools in risk and systems analysis are not unique to the labs. Private contractors are competently carrying out many of these analyses at a level appropriate to the smaller remediation sites under consideration here. The role for the laboratories is to bring (and transfer) capabilities and tools that do not exist in this community. This may be possible in three broad areas: support of laboratory remediation or characterization technologies, computer code development, and, in some special cases, support for individual cleanup sites independent of either of the above. Future inquiry may, of course, reveal others. The first two provide the best opportunities; the latter is much more limited. These are discussed below.

\section{Support for laboratory technologies.}

First, in the broader context of the CEE, many are looking to the labs for remediation or characterization technologies that the labs have developed or used themselves. It is necessary to understand the costs, technical risks, and potential benefits associated with these new technologies if they are to be used wisely. This could take the form of internal analyses and reviews of specific lab technologies that identify where a technology might be best applied and where additional development might prove advantageous. This could also take the form of partnership with private contractors working on an individual site. In applying a new technology, there may be technical risks - chances that the approach will not work as well as intended because of unexpected site or contamination characteristics. Time and resources would be lost. Site characterization uncertainties thus need to reviewed. It may be possible to reduce these uncertainties, but, again, only at the cost of time and resources. These cost/ benefit/risk issues must be developed to and balanced to choose the best overall remediation strategy for that particular site. In this context, laboratory risk management support is part of the package that comes with the laboratory remediation or characterization technology. 


\section{Software tool development}

Software tool development is a familiar means for transfer of analysis technology from the labs to others. As suggested in the previous sections, there are analysis opportunities - and hence potentially software development opportunities - in health risk assessment, site characterization, and decision analysis for cost/risk/benefit trades.

Some health risk assessment software that may be applicable to smaller sites has already been developed at the labs. The best-developed example of this is the Cal-TOX spreadsheet by Tom McKone, jointly of LLNL and the University of California, Davis. Cal-TOX models the ultimate fate of toxins released into the environment using a mass potential (fugacity) approach. As such, it uses some fairly complex chemical modeling but only a very abstract site model. The model estimates the long-term steady state partitioning of the toxin among soil, water, air, and plants. From these, the spreadsheet estimates human exposures, via contacts with the these media and with food. In many cases, this is a reasonable approach for the basic risk assessment goal of screening whether a particular level of contamination presents a hazard during a Preliminary Endangerment Assessment. In some cases, this may also be an appropriate way to define acceptable cleanup levels. The approach used by Cal-TOX represents an intermediate point between using externally mandated maximum concentration levels and site-specific detailed risk assessments.

This work also provides one model of how this software development might be coordinated. The work was sponsored by The Office of Scientific Affairs at DTSC and the specifications were carefully designed not to overlap with capabilities already present in the contractor community.

The Lawrence Berkeley SELECT program, when complete, will includes tools for more detailed modeling chemical transport and health risk. SELECT will include explicit time and spatial dependencies. SELECT is currently under active development.

Because of this existing work in risk assessment, perhaps the best outstanding opportunities for new tool development lie in other areas. Tools supporting site characterization or the development of site characterization standards could be valuable, but it will be a challenge to build tools that are broadly applicable given the considerable variability from site to site. Some site characterization tools have already been built for specific purposes. For example, at Sandia, a tool written for optimal location of a network monitoring wells is part of the larger SEDSS (Sandia Environmental Decision Support System) project. One can envision further development of this type to support a range of groundwater cleanups. 
A final area for tool development is in integration codes that organize and unify the handling of risk and uncertainty throughout the cleanup planning process. These would support both data collection and remediation decision making. Two such risk management models are in their early stages.

At Sandia, the SEDSS program is seeking to provide a tool to provide a consistent framework for decision making in the presence of uncertainty. The program is seeking to link either default or site-specific user-supplied models for sources, pathways, exposure routes and receptor response to decision analysis models supporting site characterization or technology application decisions. The emphasis is on the decision structure and the consistent handling of uncertainty more than on the component models themselves. The current prototype includes some specific support for site characterization decisions - optimization of monitoring well locations - and performs risk analysis for the groundwater pathway.

At Lawrence Berkeley, the SELECT program goes beyond the health risk analysis introduced earlier to include financial analyses of environmental remediation. The emphasis is on complete, time-dependent analysis models, so that, for example, the impacts of delaying or phasing remediation actions can be seen.

The task of developing integration tools is a very large one. Although there is some commonality, these two efforts have somewhat different emphases. Perhaps no one tool development effort can address all integration issues. Multiple activities are thus reasonable, but appropriate coordination as these efforts mature will be vital to their success.

Support for these sorts of efforts would more likely come through government channels than through responsible parties at individual sites. However, it might be reasonable to expect that codes could be protoyped at individual sites. This might even involve a partnership with one or more environmental contractors.

\section{Support for individual cleanup sites.}

Lab analysis capabilities have a more limited role at individual cleanups that do not involve tool development or demonstrations of laboratory characterization or remediation technology. If the analysis is routine, it should be done in the private sector. In many cases only such routine analyses are compatible with the time scales and resources of smaller cleanups. The situations of interest are ones where there is both a need for non-routine analysis and the resources to support them. The actual types of analyses that might be useful are the same as those introduced earlier: site characterization models to guide data collection and analysis, site-specific health risk analysis, and risk-based decision analysis to integrate all the factors going into a comparison of remediation options. The 
review conducted to date has not established any examples where this sort of interaction makes financial sense, but candidates might include the larger utility company cleanups. The more complex municipal or government cleanups might be candidates if federal funding were available. At less complex sites, a limited amount of specialized analysis, if it could minimize investment of costly site characterization or remediation work, might be appropriate. Careful coordination with the private analysis community would be vital in these cases.

Finally, there may be cases where site issues have become sufficiently contentious, either technically or politically, that a formal analysis of the uncertainties by an independent party such as the labs might be warranted. Many redevelopment projects do have a significant political dimension. The proposed development at the Hickmott Cannery site in Antioch spawned a lively city planning and permitting debate. At the national level, issues of risk and uncertainty certainly have entered the political debate. None the less, such an independent review role for the labs is speculative; it is far from clear exactly under what circumstances the labs might become involved.

\section{Concluding Comments: Managing The Relationships}

The previous sections have identified three risk-based analysis roles for the laboratories in state-level site cleanups. All three of these go beyond simple risk assessment. These are

- Support for laboratory remediation and characterization technologies

- Development of computer or analysis tools

- Participation in risk and systems analysis at individual cleanups

In all of these, two types of relationships must be carefully managed. The obvious interaction is the organizational relationship between the labs and the private sector. Much has been said about this above. This relationship must be managed so the labs carry out a unique role and do not compete. The real economic and financial constraints must be respected.

The less obvious interaction is the technical relationship between laboratory analysts and site experts both private and governmental. Risk and systems analyses bring together normative tools - the mathematical tools supporting the management of uncertainty and the structuring of complex decisions - and substantive knowledge - information about the particular issue. In site remediation, substantive knowledge may be drawn from chemistry, geology, toxicology, and economics. Considerable effort is often needed to understand how to best link these two kinds of knowledge. The laboratory analysis community can bring very strong mathematical tools to support site remediation 
analysis. Other groups at the labs, at DTSC, and in the private consultant community must contribute the substantive knowledge.

The CEE's role in efficiently managing these relationships will be vital to the effective application of the laboratories' technical expertise in remediating smaller contaminated properties. 


\section{UNLIMITED RELEASE}

INITIAL DISTRIBUTION

Rebekah Buckles

Institute of Environmental Solutions

717 K Street, Suite 224

Sacramento CA 95814

Norm Goldstein

Lawrence Berkeley Laboratory

Earth Science Division, B-50E

1 Cyclotron Road

Berkeley CA 94720

Robert Johnson

Lawrence Berkeley Laboratory

Deputy Director's Office

Building 50A, Room 4119

1 Cyclotron Road

Berkeley CA 94720

Jeff Lenhert

US DOE

Albuquerque Operations Office/ ETDD

Building 384, 3rd. Floor

P.O. Box 5400

Albuquerque, NM 87185-5400

Paul Longsworth

US/DOE EM-521

Cloverleaf Building

19901 Germantown Road

Germantown MD 20874

Amy Moran

US DOE

Oakland Operations Office / TPD

1301 Clay Street

Oakland CA 94612-5208 
Joe Paladino

US/DOE EM-521

Cloverleaf Building

Germantown, MD 20874

Tom Parker

Interagency Environmental Technologies Office

955 L'Fant Plaza North, S. W.

Washington D.C. 20024

Allan Wolfenden

Department of Toxic Substance Control

10151 Croyden Way, Suite 3

Sacramento, CA 95827

Richard C. Ragaini, LLNL, L-626

MS-9053 T. T. Bramlette, $8106(20)$

MS-9201 J. T. Ringland, 8112 (15)

MS-0719 J. E. Nelson, 6621

MS-0726 J. B. Woodard, 6600

MS-0727 M. S. Y. Chu, 6622

MS-0728 D. L. Berry, 6602

MS-0756 G. C. Allen, 6607

MS-1326 P. G. Kaplan, 6312

MS-1335 F.W. Bingham, 6301

MS-1337 D. E. Ellis, 6300

MS-1345 D. P. Gallegos, 6331

MS-1345 E. K. Webb, 6331

MS-9001 J. C. Crawford, 8000

Attn: E. E. Ives, $5200 \quad$ MS-9006

J. B. Wright, 5300 MS-9005

R. J. Detry, 8200 MS-9037

W. J. McLean, 8300 MS-9054

L. A. Hiles, 8400 MS-9105

P. N. Smith, $8500 \quad$ MS-9002

L. A. West, $8600 \quad$ MS-9901

R. C. Wayne, 8700 MS-9401

T. M. Dyer, $8800 \quad$ MS-9141

D. L. Crawford, 8900 MS-9003

MS-9004 M. E. John, 8100 


$\begin{array}{ll}\text { MS-9011 } & \text { R. E. Palmer, } 8901 \\ \text { MS-9014 } & \text { D. R. Henson, } 5371 \\ \text { MS-9016 } & \text { J. Dexter, } 9209 \\ \text { MS-9036 } & \text { W. Bolton, 8102 } \\ \text { MS-9052 } & \text { D. R. Hardesty, } 8361 \\ \text { MS-9052 } & \text { G. A. Fisk, 8355 } \\ \text { MS-9056 } & \text { J. Vitko, 8102 } \\ \text { MS-9101 } & \text { W. C. Piela, } 8411 \\ \text { MS-9103 } & \text { G. Thomas, 8111 } \\ \text { MS-9105 } & \text { L. A. Hiles, } 8400 \\ \text { MS-9201 } & \text { L.D. Brandt, 8112 } \\ \text { MS-9201 } & \text { R. W. Wheeler, } 8112 \\ \text { MS-9201 } & \text { C. Shen, 8112 } \\ \text { MS-9222 } & \text { T. Larson, } 9644 \\ \text { MS-9222 } & \text { M. E. Brynildson, } 8644 \\ \text { MS-9403 } & \text { J. E. Costa, 8711 } \\ \text { MS-9404 } & \text { J. C. F. Wang, 8713 } \\ \text { MS-9406 } & \text { H. H. Hirano, 8412 } \\ \text { MS-9410 } & \text { J. C. Swearengen, 8113 } \\ \text { MS-9410 } & \text { B. Zaragoza, 5361 } \\ \text { MS-9671 } & \text { A. Johnson-Duarte, } 8281 \\ \text { MS-9671 } & \text { J. J. Bartel, 8281 }\end{array}$

MS-9021 Technical Communications Department, 8535, for OSTI (10)

MS-9021 Technical Comm. Department, 8535/Tech. Library, MS 0899, 13414

MS-0899 Technical Library, 13414 (4)

MS-9018 Central Technical Files, 8523-3 (3) 